\title{
Comprometimento e interação na coordenação de projetos de edifícios: um estudo de caso
}

\author{
Commitment and interaction in building design \\ coordination: a case study
}

\section{Vinícius Carrião dos Santos \\ Tatiana Gondim Amaral \\ J osé de Paula Barros Neto}

\section{Resumo}

A

ineficácia e a ineficiência dos comprometimentos estabelecidos dentro da equipe de projeto de edifícios acarretam perdas como retrabalhos, atrasos e custos adicionais de serviços para as fases seguintes do empreendimento e fragilizam os relacionamentos interpessoais entre os envolvidos. Esta pesquisa investiga a contribuição da interação no estabelecimento dos compromissos entre os participantes de equipes de projetos de edifícios no âmbito da coordenação de projetos. A pesquisa, de caráter qualitativo e exploratório, foi estruturada por meio de um estudo de caso relacionado à coordenação de projetos de edifícios. Como resultados percebe-se a dinâmica das ações envolvidas no comprometimento e apontam-se medidas práticas que podem auxiliar na melhoria do comprometimento dos agentes envolvidos, na avaliação e ajuste do processo enquanto o desenvolvem, assim como no aprimoramento das habilidades comunicativas de cada participante. O estudo evidenciou a influência determinante da interação, como instrumento de comprometimento, que relativiza a contribuição de protocolos e de ferramentas de controle adotadas para o processo, assim como a confiabilidade das informações documentadas.
\end{abstract}

Palavras-chaves: Coordenação de projetos. Análise da conversa. Comprometimento.

Vinícius Carrião dos Santos Instituto Federal de Educação, Ciência e Tecnologia de Goiás Goiânia - GO - Brasil

Tatiana Gondim Amaral Universidade Federal de Goiás Goiânia - GO - Brasil

J osé de Paula Barros Neto Universidade Federal do Ceará Fortaleza - CE - Brasil

Recebido em 20/02/17 Aceito em 26/06/17

\section{Abstract}

The ineffectiveness and inefficiency of the commitments made within building project teams cause waste due to rework, delays and additional costs for the subsequent phases of the project, in addition to undermining interpersonal relationships. This research study investigates how commitments are made through interactions between participants of the project coordination team. This is a qualitative and exploratory study conducted through a case study in building project coordination. The results revealed what actions are more closely linked to commitment and also enabled us to suggest guidelines to help agents to improve their communication skills and grasp their commitments as set out in the workplace by providing means to assess and adjust the process throughout its development. This study made evident the determinig character of interaction, as an instrument to establish commitments, which puts at a second plane the contribution of protocols and control tools adopted for the work process, as well as the reliability of the documented information.

Keywords: Design coordination. Conversation analysis. Commitment. 


\section{Introdução}

Na gestão da elaboração do projeto de edifícios são identificados problemas como a deficiência das informações reunidas, as falhas de comunicação, a falta de entrosamento entre os técnicos envolvidos, a coordenação do elevado número de especialistas e o trabalho à distância e com equipes multinacionais, entre outros.

O comprometimento deficiente entre os agentes participantes de um projeto prejudica o trabalho de toda a equipe, assim como seus resultados. Compromissos efetivos minimizam as chances de serem descumpridos, são confiáveis e resultam na ampliação da eficiência do processo de projeto, facultando a melhoria da qualidade dos projetos em seus aspectos de desempenho, de construtibilidade e estéticos (WEIGAND; POLL; MOOR, 2003; OLIVEIRA, 2010; MITIDIERI; MANSO, 2011).

O comprometimento é feito através da interação e da comunicação, e o caráter daquele é mediado pelas ações e comportamentos dos agentes envolvidos. Compreender como essas ações acontecem na prática pode auxiliar no aprimoramento da gestão e da coordenação do processo de projetos.

Por isso vêm sendo criadas soluções de gestão para facilitar o processo de projeto e seu controle, como o Last Planner (BALLARD, 2000) e o Lean Design Delivery System (BALLARD; ZABELLE, 2000), no contexto da filosofia enxuta, o Project Partnering (EMMITT, 2010), que associa estratégias relacionais e contratuais, e o Integrated Project Delivery (IPD) (GHASSEMI; BECERIKGERBER, 2011), cujas soluções ligam aspectos gerenciais a ferramentas da tecnologia da informação.

Essas soluções destacam aspectos comuns como a relevância da integração e da colaboração entre os agentes participantes de um projeto (BAIDEN; PRICE; DAINTY, 2006; EL REIFI; EMMITT, 2011). Esses aspectos foram os pontos de partida para pesquisas dedicadas às questões da comunicação e do relacionamento humano a partir do estudo de projetos reais, como Otter e Emmitt (2008), que investigaram como se dá a conversa entre os membros da equipe de projeto; Luck (2009), que apresentou como a concepção de um projeto é influenciada pela fala; Gorse e Emmitt (2009), que examinaram a contribuição da conversa informal em reuniões de gerenciamento; Oak (2011, 2012), que pesquisou as relações entre a prática de projetar e a fala; Blois et al. (2011), que se dedicaram à interdependência entre coordenação e comunicação; e Zerjav, Hartmann e Achammer
(2013), que estudaram o manejo da interdisciplinaridade no ambiente de projeto.

O presente trabalho, tal como algumas dessas pesquisas, dedica-se ao estudo da interação como recurso para a compreensão da gestão na construção civil mediante o uso de técnicas analíticas oriundas de campos científicos distintos da engenharia, como as ciências sociais e a linguística, como fizeram Luck (2009), Matthews e Heinemann (2012) e Oak (2011, 2012) para a investigação do processo de projeto.

Esta pesquisa também amplia as áreas da construção civil já investigadas por estudos desse gênero desenvolvidos no país. Costa (2007) e Oliveira (2010), por exemplo, focaram a comunicação na gestão da produção no canteiro de obras, enquanto este estudo concentra-se no trabalho da equipe de projeto e avança para além do que se é dito, aprofundando nas estruturas da linguagem.

Investigou-se o estabelecimento dos compromissos em equipes de coordenação de projetos a partir dos elementos interacionais da fala com o intuito de delinear medidas práticas que favoreçam o comprometimento eficaz e ampliem o ferramental utilizado no processo de gestão do contexto estudado.

\section{Fundamentação teórica}

\section{Pedidos, promessas e comprometimento}

O ciclo de comprometimento promovido pela construção enxuta através do Last Planner (BALLARD, 2000) e apresentado na Figura 1 busca consolidar o entendimento de que as organizações podem ser compreendidas como estruturas nas quais a coordenação da ação se dá através da conversa, mais especificamente ao serem feitos pedidos e promessas entre os clientes e os executores dentro do processo produtivo. $\mathrm{O}$ ciclo de comprometimento define uma estratégia para que os compromissos sejam estabelecidos, conduzidos e mantidos por meio da comunicação, e os pedidos e as promessas declarados pelos agentes envolvidos podem ser aceitos, negados, contrafeitos ou retirados.

Caracterizam o ciclo de comprometimento:

(a) a necessidade de verbalização das ações: "Eu farei isto!" ou "Pronto!";

(b) pedidos e promessas constituem requisitos a serem atendidos dentro do ciclo para que haja a 
continuidade das tarefas do processo de modo racionalizado; $\mathrm{e}$

(c) a ocorrência de contingências demandam que o ciclo seja reiniciado, exigindo que o agente tenha domínio do completo funcionamento do sistema de compromissos.

Em função disso, a operação do ciclo carece de treinamento dos agentes, pois o ciclo de comprometimento funciona com critérios bem definidos.

No entanto, a rigorosa estrutura funcional do ciclo subutiliza os recursos dos atos da fala por não atentar ao conteúdo que subsidia as interações e por não facultar o compartilhamento de significados. Não há momentos específicos na estrutura do ciclo para que os participantes do processo exponham como compreendem o que estão vivenciando, que os estimulem a dar sugestões e emitir opiniões, assim como para que contribuam com melhorias para o processo e para os resultados diante dos conceitos elaborados como equipe (GOLDKUHL, 2003).

Compartilhar significados é essencial para o pleno alcance do ajustamento mútuo nas relações de trabalho requeridas pelo ambiente de incerteza das organizações contemporâneas, relacionada à elevada concorrência, à alta rotatividade de pessoal e ao atendimento a diferentes nichos de mercado, entre outros (WEIGAND et al., 2003; ERIKSSON; LIND, 2005).

Ao dedicaram-se ao estudo do comprometimento na construção civil com o uso do Last Planner, Viana, Formoso e Isatto (2011) concluíram que a complexidade da prática do gerenciamento exige esforços e capacidades do gestor que extrapolam a adoção de sistemas de gestão e comunicação, tal como afirmaram Ericksson e Lind (2005). Estes autores defendem que o uso de softwares tem eficiência limitada no gerenciamento do compromisso se os próprios envolvidos não se reconhecerem como interdependentes para a conclusão do projeto.

Sull e Spinosa (2007) estabelecem que esse gerenciamento deve ser uma ferramenta, e não um sistema, uma vez que atentar para a forma como os compromissos são feitos e focar nas negociações é mais econômico e simples que alterar toda uma estrutura de organização de processos já consolidada em uma empresa.

Assim, as discussões provenientes da necessidade do comprometimento - "Preciso de seu comprometimento para que alcancemos este resultado" - são mais importantes que o conteúdo dos termos da promessa - "Você deve me fornecer tudo o que está listado aqui, está bem?”. O comprometimento efetivo, portanto, exige negociação cuidadosa, sustentada por uma comunicação explícita, de mão dupla e respeitosa, além da compreensão dos aspectos interacionais e comportamentais inerentes a sua caracterização (BAMBACAS; PATRICKSON, 2008; ZEFFANE; TIPU; RYAN, 2011).

Com o objetivo de melhorar o processo de gestão têm-se desenvolvido estratégias que permitem às equipes de trabalho compartilhar a compreensão do processo que os reúne e também oportunizar o alinhamento entre os envolvidos (OLIVEIRA, 2010). Com essa finalidade foram criadas e experimentadas na construção civil dinamarquesa, e estudadas por Emmitt (2010), as Facilitated Workshops (reuniões facilitadas).

Figura 1 - Ciclo do comprometimento

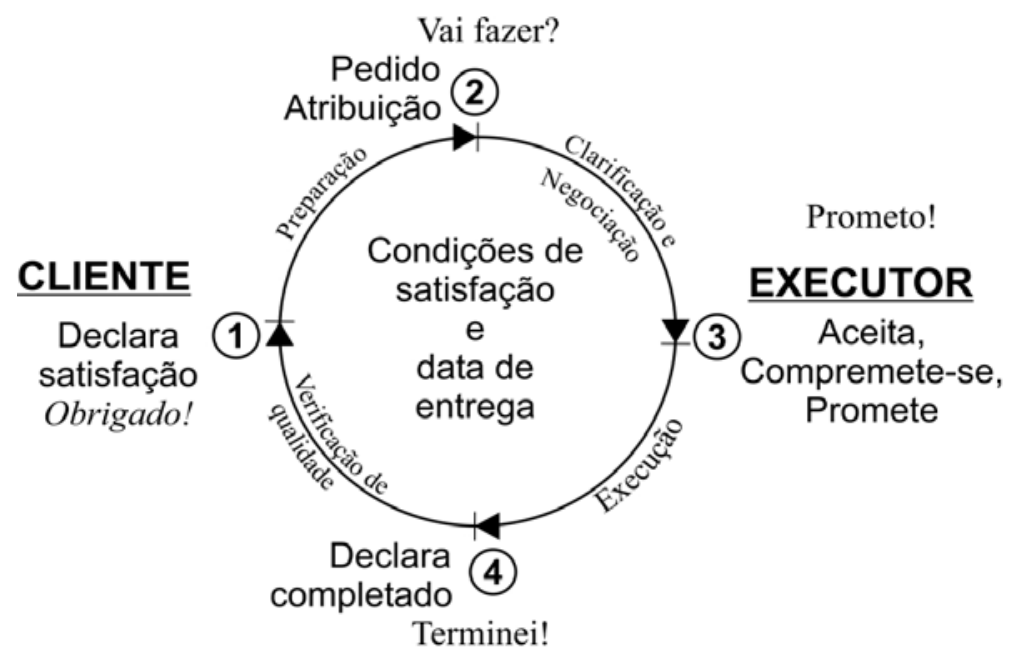

Fonte: Macomber e Howell (2003). 
Essas reuniões são organizadas com finalidades específicas e antecedem o efetivo processo de planejamento do empreendimento, de modo a proporcionar aos envolvidos, desde contratantes a fornecedores e usuários, momentos para troca de experiências, para o nivelamento quanto à terminologia, para discussão de benefícios comuns e dos valores a serem incorporados ao projeto. É determinante o papel do facilitador nessas reuniões, o qual tem a tarefa de estimular a interação e orientar o atendimento dos objetivos delas.

Portanto, comprometer-se está além de emitir uma promessa, como estabelecido pelo ciclo de comprometimento, ainda que se equivalham a obrigação assumida de forma oral ou escrita. Dois aspectos do comprometimento são determinantes para a coordenação da ação: aqueles provenientes dos indivíduos e os que emanam da forma como o trabalho da equipe é realizado.

O componente individual do comprometimento resulta do balanceamento do conjunto de disposições internas que motivam cada agente do processo. Meyer e Herscovich (2001) descrevem que esse conjunto reúne disposições de desejo, de obrigação e de necessidade (também chamada de custo), que se revelam nos comportamentos dos indivíduos a partir do estabelecimento dos objetivos almejados para o grupo, conforme apresentado na Figura 2. Cada tipo de disposição interna é identificado por meio dos aspectos relativos aos interesses de cada participante da equipe (bases).
A efetividade do comprometimento revela-se na predominância das disposições de desejo, assim, quando os indivíduos, instados a se comprometerem, desejam agir porque se identificam ou compartilham valores com o grupo com o qual estão envolvidos, menos sensíveis eles são às limitações, restrições ou contingências que se impõem ao processo para se chegar ao resultado almejado para o trabalho da equipe. O foco mental é a obtenção dos resultados.

Por outro lado, quando os indivíduos querem escapar à obrigação, prevalecendo internamente disposições de obrigação ou necessidade, facilmente são evidenciadas e destacadas as adversidades e dificuldades para a realização do trabalho. Aquele que se vê comprometido pela necessidade inclina-se a encontrar formas de escapar ao comprometimento e se aterá estritamente aos termos do compromisso a que se propõe.

Neste modelo, o caráter do comprometimento revela-se pelos comportamentos dos agentes envolvidos, que, por sua vez, são determinados pelo balanço entre as disposições internas de cada um. Há comportamentos focais que evidenciam claramente a disposição interna predominante nos agentes e há comportamentos discricionários, que demonstram de maneira indireta a hierarquia das disposições internas dos participantes.

Figura 2 - Modelo do comprometimento organizacional

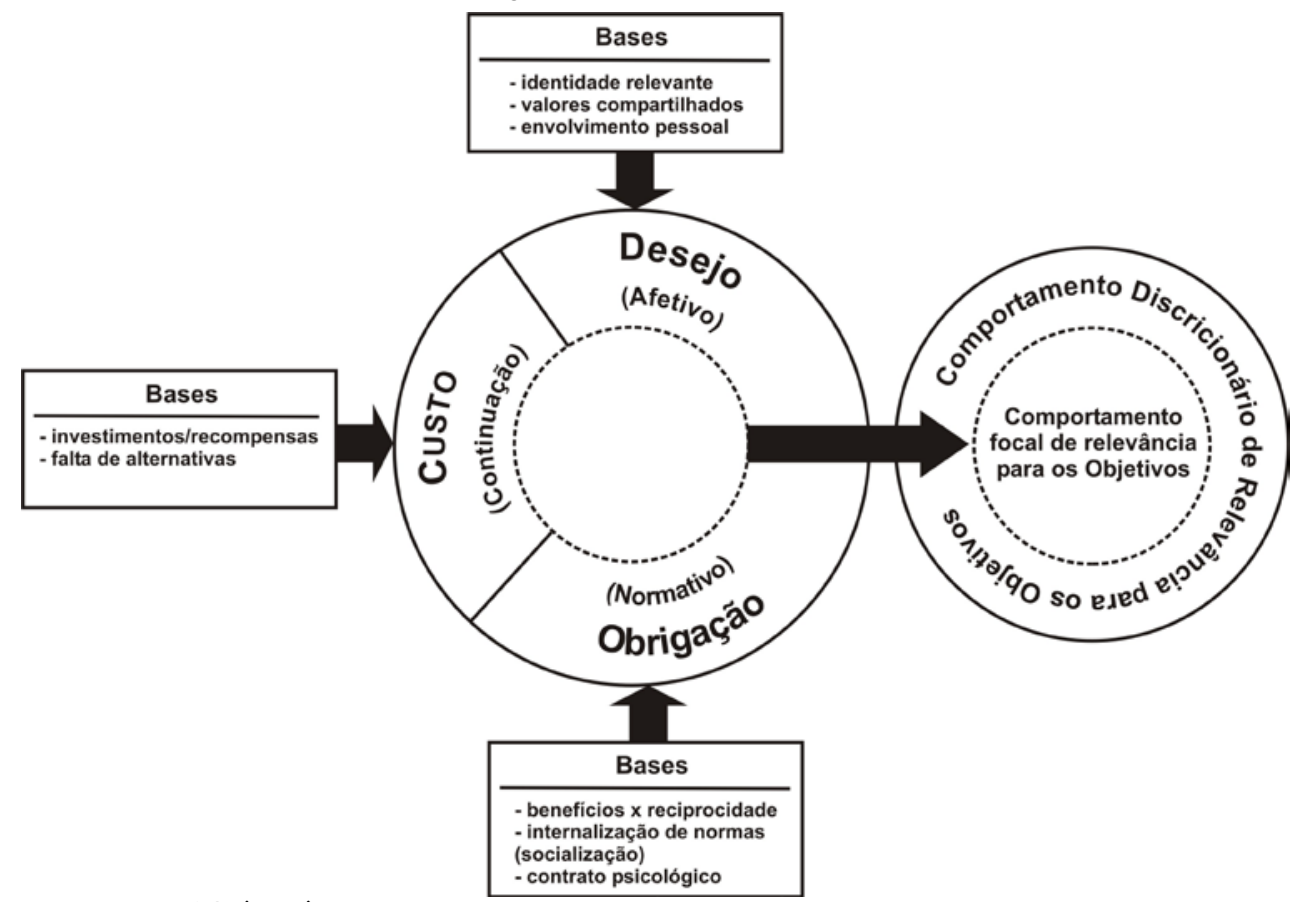

Fonte: Meyer e Herscovich (2001). 
Os comportamentos dos membros de uma equipe são fortemente influenciados pela forma como o trabalho do grupo é realizado, o que afeta a efetividade do comprometimento. A interdependência entre as atividades, a complexidade delas e a autonomia do grupo são determinantes para os comportamentos da equipe. Rousseau, Aubé e Savoie (2006), a partir das definições de Meyer e Herscovich (2001) e da compreensão de que o desempenho eficaz é resultante da capacidade do grupo de controlar e avaliar as próprias ações, elaboraram uma abordagem conceitual das dimensões comportamentais envolvidas no trabalho de equipe.

Essas dimensões particularizam os comportamentos focais da equipe de trabalho em ação, caracterizando o contexto de trabalho. Portanto, para que uma equipe alcance os resultados almejados com o máximo aproveitamento do trabalho compartilhado é preciso que os comportamentos individuais observados na interação entre os membros do grupo evidenciem ou sejam orientados para as dimensões comportamentais apontadas no modelo conceitual apresentado na Figura 3.

A dimensão de comportamentos funcionais de colaboração, por exemplo, precisa ser necessariamente identificada em uma equipe de coordenação de projetos de edifício, caso contrário o grupo não conseguirá alcançar satisfatoriamente os objetivos do trabalho, que é a elaboração de todo o material para a produção do edifício.

Atitudes individuais que promovam a coordenação, a cooperação e a troca de informações devem ocorrer e ser percebidas pelos envolvidos, ainda que individualmente haja agentes movidos por disposições de obrigação, como alguém que se considere apenas como um funcionário de uma empresa participante que não se sinta intimamente envolvido com os desafios do trabalho.

Para aquele que lidera a equipe, a compreensão dessas dimensões comportamentais e das prováveis disposições individuais adquire uma dupla faceta, uma vez que ele é simultaneamente participante da equipe e agente responsável por conduzir o grupo para atingir os objetivos do trabalho.

As competências individuais de gestores, como líderes de equipe e coordenadores, ligadas à comunicação e ao relacionamento influenciam tanto a orientação do caráter do comprometimento quanto a produtividade. Para a efetividade do comprometimento interessa, portanto, não só a forma como a mensagem é transmitida, mas também a maneira como a equipe é conduzida (BAMBACAS; PATRICKSON, 2008).

\section{Figura 3 - Estrutura hierárquica do comportamento da equipe de trabalho}

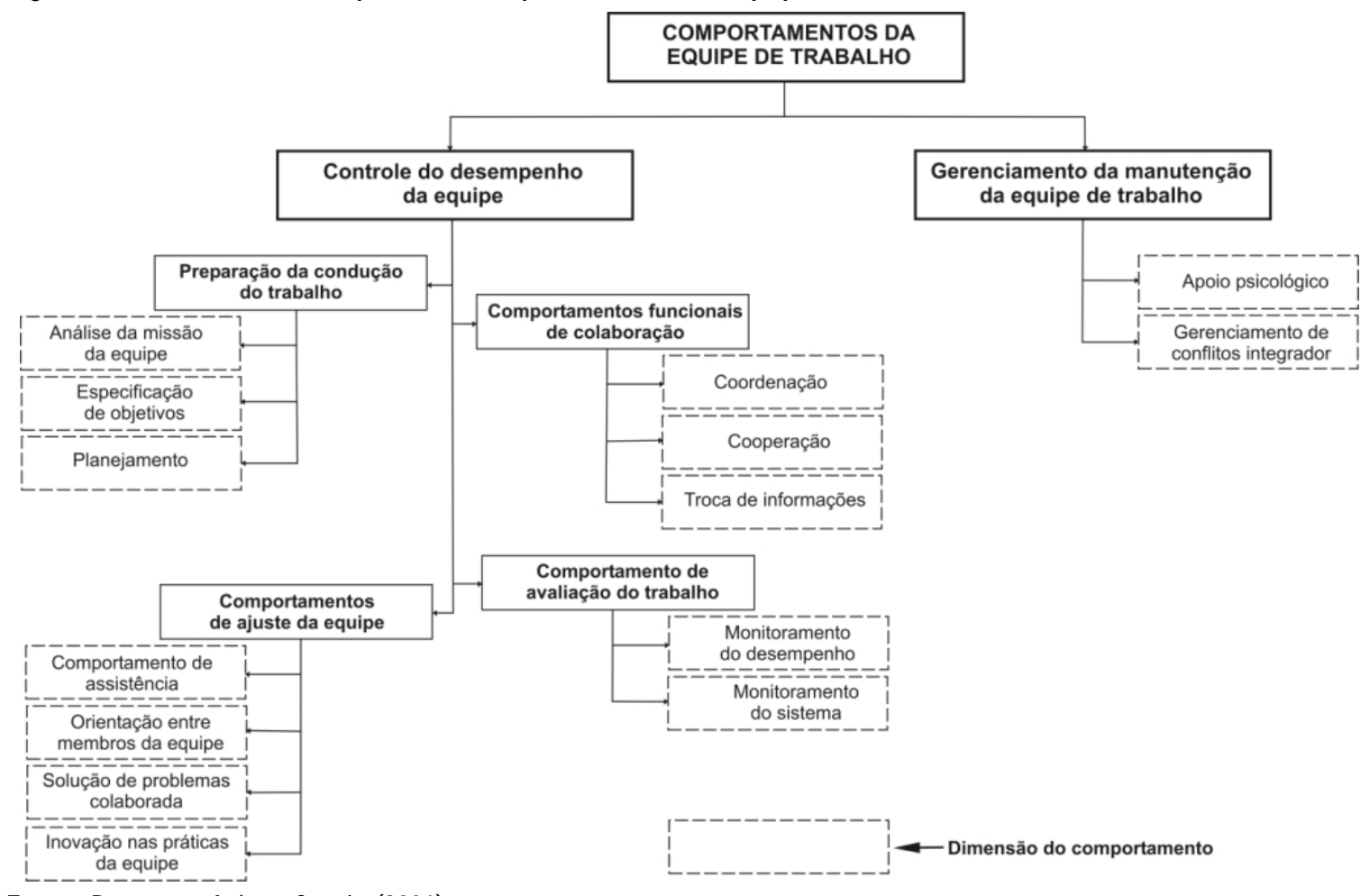

Fonte: Rousseau, Aubé e Savoie (2006). 
Clareza, síntese, persuasão, capacidade crítica, escuta ativa, empatia, abertura e capacidade de relatar e prestar esclarecimentos solicitados são habilidades comunicativas que, associadas à liderança e à confiança, constituem competências interpessoais essenciais para facultar comprometimentos eficazes (BAMBACAS; PATRICKSON, 2008; ZEFFANE; TIPU; RYAN, 2011). Essas habilidades, embora presumíveis e por vezes inatas, precisam ser identificadas e desenvolvidas nos líderes e coordenadores para que conduzam de maneira efetiva os esforços em prol dos objetivos do trabalho e da atuação integrada do grupo.

\section{Análise da conversa}

A abordagem que fundamenta o ciclo de comprometimento é simplista e excludente ao considerar que as organizações são redes de pedidos e promessas, segundo Goldkuhl (2003). Para ele, o estabelecimento de categorias para os atos da fala deve emanar da própria interação, sendo definida pelos envolvidos, e sugere a Análise da Conversa (SACKS; SCHEGOLFF; JEFFERSON, 1974) como estratégia para se entender a interação na coordenação de ações, pois há aspectos que intervêm nas ações provenientes da fala, como o monitoramento mútuo entre os falantes, a comunicação não verbal e a construção do significado da interação, que não são considerados pelo ciclo do comprometimento.

A Análise da Conversa (AC) surgiu das ciências sociais nos anos 1960 a partir dos estudos de Harvey Sacks, que investigaram a conversa real e gravada com um método que possui reprodutibilidade e “descritibilidade” científica, sem depender de observações estatísticas para isso. A AC demonstrou a viabilidade da observação natural para o estudo da ação social sem fundamentar-se exclusivamente na capacidade intelectual e na abstração do pesquisador, como a abordagem teórica da comunicação que fundamenta o ciclo de comprometimento (GOODWIN; HERITAGE, 1990; SCHEGLOFF, 1989).

A AC não interpreta o que significa uma expressão dita e as intenções, ou como um ouvinte a interpretou, e diferencia-se da Análise do Discurso por não se deter nas construções ideológicas que suportam a fala (GOODWIN; HERITAGE, 1990).

\section{Método \\ Objeto de pesquisa, o método e a coleta de dados}

Realizou-se um estudo de caso exploratório da coordenação de projetos de dois empreendimentos distintos desenvolvidos por um escritório de arquitetura e coordenação de projetos complementares.

O estudo concentrou-se nos momentos de elaboração dos compromissos de prazo nas reuniões de coordenação de projetos complementares. A fala e a interação não verbal foram os principais recursos utilizados para a análise da estruturação dos compromissos, associados à avaliação da documentação do processo na qual esses compromissos foram registrados e pela qual eram acompanhados.

Para o estudo de caso escolheu-se um escritório de coordenação de projetos que tivesse um sistema de gestão da qualidade (SGQ) operante e certificado, indicando que o escritório possui práticas de controle e gestão bem definidas, para as quais o comprometimento é uma atividade precípua e valorizada no processo.

Empregou-se a AC como técnica de análise de dados que se processa através da interpretação direta das falas transcritas das gravações de áudio ou vídeo, segundo a legenda adotada por Gago (2002) e apresentada na Figura 4. Em função disso foram adotados como instrumentos para a coleta de dados a observação direta (não participante), os registros de áudio e vídeo e a análise documental. Na Figura 5 estão detalhados os dados de interesse e onde foram aplicados os instrumentos de coleta de dados.

A técnica de análise da AC consiste em descrever as ações dos participantes da interação através da identificação de como as estruturas básicas da conversa e as estratégias de interação organizadas pela AC são utilizadas pelos falantes (HERITAGE, 2004; SILVA; ANDRADE; OSTERMANN, 2009). Assim se pode caracterizar a forma de organização da interação que foi construída pelos agentes e quais estratégias interacionais foram adotadas para o estabelecimento dos compromissos, e avaliar a contribuição da sequência de interação e dos comportamentos para a efetividade do comprometimento.

São estruturas básicas da conversa:

(a) a unidade de construção de turno (UCT), isto é, a fala de uma pessoa que tem início e fim;

(b) o aproveitamento dos intervalos entre as UCT para que algum participante assuma a vez de fala; 
(c) a existência ou não de uma forma predeterminada de seleção da ordem de fala (sistema de tomada de turno);

(d) o ajuste ao interlocutor feito pelo falante ao escolher estratégias de interação em função de quem o ouvirá;

(e) os reparos à UCT que não foram compreendidas;

(f) as justificativas; e

(g) a elaboração de UCT que favoreçam a concordância do ouvinte, entre outros (affiliative actions) (GOODWIN; HERITAGE, 1990; SILVA; ANDRADE; OSTERMANN, 2009).
As estratégias interacionais resultam, sobretudo, da forma como as estruturas básicas são utilizadas ou arranjadas para que o falante se faça entendido, para atribuir um sentido específico para suas palavras ou orientar a resposta que deseja. A elaboração prévia e ordenada de uma UCT (projeto de turno), a escolha lexical, provocações, associação de expressões verbais e não verbais, o uso de preâmbulos para se fazerem questionamentos, ironia, piadas e formulações são exemplos de estratégias de interação caracterizadas pela AC (HERITAGE, 2004; SILVA; ANDRADE; OSTERMANN, 2009).

\section{Figura 4 - Legenda adotada nas transcrições}

\begin{tabular}{|c|c|c|}
\hline Convenção & Designação & Uso \\
\hline [texto] & colchetes & Sobreposição de falas \\
\hline$=$ & igual & $\begin{array}{l}\text { Falas emendadas ou dar sequência a turnos com } \\
\text { sobreposições }\end{array}$ \\
\hline (1.2) & Pausa & Pausa na fala medida em décimos de segundo \\
\hline (.) & Micropausa & Pausa rápida em intervalo menor que 0.2 segundo. \\
\hline . & Ponto final & Entonação descendente no final da fala \\
\hline ? & Interrogação & Entonação ascendente no final da fala \\
\hline , & Vírgula & Entonação ascendente temporária ou breve \\
\hline$\downarrow$ & Seta para baixo & Entonação descendente (ênfase mais definida) \\
\hline$\uparrow$ & Seta para cima & Entonação ascendente (ênfase mais definida) \\
\hline- & Hifen & Interrupção abrupta da frase ou palavra \\
\hline$\underline{\text { texto }}$ & Sublinhado & $\begin{array}{l}\text { Ênfase pela elevação do volume da fala (caracterizada pela } \\
\text { oscilação. Associada aos dois pontos) }\end{array}$ \\
\hline$: \cdots:$ & Dois pontos & $\begin{array}{l}\text { Ênfase pelo alongamento do som de vogais ou consoantes } \\
\text { (caracterizada pela oscilação. Associada ao sublinhado) }\end{array}$ \\
\hline$>$ texto $<$ & $\begin{array}{l}\text { Maior que menor } \\
\text { que }\end{array}$ & Trecho pronunciado mais rapidamente que a fala normal \\
\hline$<$ texto $>$ & $\begin{array}{l}\text { Menor que maior } \\
\text { que }\end{array}$ & Trecho pronunciado mais lentamente que a fala normal \\
\hline${ }^{\circ}$ texto $^{\circ}$ & Símbolo de graus & Indica fala de baixo volume ou sussurro \\
\hline TEXTO & Maiúsculas & Indica fala de volume elevado ou gritado \\
\hline ftexto£ & Libra inglesa & Indica fala associada a sorrisos \\
\hline (hhh) & & Variação de risos \\
\hline hhh & & Aspiração audivel \\
\hline .hhh & & Inspiração audivel \\
\hline ( texto ) & Parentese & Transcrição duvidosa \\
\hline$(($ texto $))$ & Parenteses duplos & Comentário do transcritor ou registro de ação não verbal \\
\hline$[1-1]$ & & Identificação de trecho [linha até linha] \\
\hline
\end{tabular}

Fonte: Gago (2002). 
Figura 5 - Técnica de análise e instrumentos de coleta de dados da pesquisa

\section{Técnica de Análise}

\section{Instrumentos de coleta de dados}

Dados de interesse

Organização e desenvolvimento das RPI

Configuração da sala de reuniões

Chegada e saida dos membros da equipe

Posicionamento de participantes na mesa

\section{ANÁLISE DA CONVERSA}

Evidencia a forma de organização da interação e as ações promovidas através da fala e da perspectiva de cada participante.

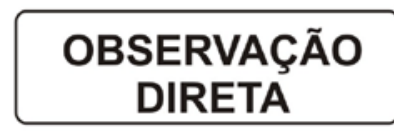

\section{ANÁLISE DOCUMENTAL}

REGISTRO DE ÁUDIO

Procedimentos e registros do SGQ Documentos da coordenação de projetos complementares

Interação pela fala
Onde se aplicou

Empreendimentos 1 e 2

Empreendimentos 1 e 2

Empreendimentos 1 e 2

\section{REGISTRO} DE VÍDEO
A necessidade de acompanhamento e gravação das reuniões assim como a utilização dos dados foi apresentada aos diretores do escritório mediante um termo de compromisso com o qual anuíram, responsabilizando-se por esclarecer aos demais colaboradores do escritório e clientes quais registros seriam feitos e sua finalidade. No entanto, antes de cada uma das reuniões o pesquisadorobservador questionou os participantes de modo a constatar a real disponibilidade dos envolvidos, respondendo a dúvidas quanto ao teor da pesquisa, e nenhum dos participantes das reuniões se manifestou contrário aos registros.

A transcrição das falas da reunião do empreendimento 1 (E1), ocorrida antes da reunião do empreendimento 2 (E2), indicou que a realização do registro de vídeo era essencial para a pesquisa, visto que a análise do áudio de E1 foi dificultada pela falta de registro das ações não verbais. A percepção das ações não verbais através do áudio foi apenas parcial e limitada a elementos de apoio à linguagem, como risos, onomatopeias e ruídos.

A dificuldade vivenciada nessa análise demonstrou que as ações não verbais vinculam-se à fala completando-a e que no contexto estudado essas ações não verbais constituem importante componente da comunicação, um fato que se alinha às conclusões de Otter e Emmitt (2008) e de Oak (2011) quanto à preferência apontada por projetistas por reuniões presenciais como recurso para a troca de informações e tomada de decisões de um grupo.

Nos dois empreendimentos analisados, dezenove relatórios de desenvolvimento de projetos (RDP) e duas atas de reunião foram consultados, e do total de 4 h e 40 min de gravação das duas reuniões foram transcritos $31 \mathrm{~min}$.

Os RDP são registros estabelecidos nos procedimentos do manual da qualidade do escritório no qual estão listadas todas as atividades programadas para cada disciplina de projeto do empreendimento, suas respectivas previsões de início e término, assim como campos para a caracterização do status da atividade e comentários. Esses relatórios, atualizados quinzenalmente, foram acompanhados com o intuito de se verificar o cumprimento dos compromissos de prazo estabelecidos nas reuniões.

Nas atas das RPI são registradas apenas as decisões relativas às soluções de projeto e de tecnologias ou suas respectivas modificações, sendo os compromissos de prazo fixados no cronograma de execução de projetos (CEP) que subsidia os dados do RDP.

\section{Caracterização do escritório estudado e dos empreendimentos analisados}

O escritório possui uma década de atuação no mercado, e sua experiência em projetos de edifícios de multipavimentos residenciais e comerciais, assim como a familiaridade com as necessidades e demandas dos clientes podem ser atestadas em função dos mais de 60 empreendimentos desse tipo que predominam no portfólio da empresa, elaborados para 20 construtoras e incorporadoras distintas do centro-oeste brasileiro. Dois diretores são responsáveis pelas atividades de produção e administração, e contam com uma equipe de vinte profissionais, dezoito destes arquitetos.

Definiram-se três critérios para a seleção dos contratos analisados: projetos que tivessem as maiores e mais variadas equipes multidisciplinares, projetos que oferecessem novos desafios ao escritório de arquitetura e projetos que 
concentrassem recursos e ferramentas variadas de comunicação.

A diretoria do escritório colaborou com o estudo apresentando os contratos vigentes em estágio inicial de desenvolvimento que pudessem atender às definições de seleção, uma vez que nenhum dos pesquisadores pertencia ao quadro técnico do escritório ou tinha conhecimento prévio dos contratos em andamento.

O acompanhamento da coordenação de projetos dos dois empreendimentos escolhidos, caracterizados no Quadro 1, estendeu-se por dezesseis meses, e após as reuniões de coordenação de projetos complementares gravadas, denominadas no escritório de reuniões de partida de instalações (RPI), os trabalhos de coordenação de projetos dos empreendimentos continuaram sendo monitorados através do RDP até o término da pesquisa e nenhum dos empreendimentos teve seus projetos concluídos e entregues ao cliente até essa data. Tanto no E1 quanto no E2 as soluções de projetos, os empreendedores, as localidades e os projetistas complementares foram distintos, assim como a forma de desenvolvimento do projeto.

Em E1 o desenvolvimento do projeto se deu de forma tradicional, com a compatibilização feita através da sobreposição de projetos e verificação manual de incompatibilidades. Em E2 todos os projetos foram modelados em softwares BIM e compatibilizados virtualmente com o software Navis.

\section{Reuniões de coordenação como conversas institucionais}

Para a AC reuniões são situações de fala com objetivo definido nas quais se busca o entendimento compartilhado entre os participantes, o que constitui um sistema específico de interação pela fala denominado conversa institucional (SACKS; SCHEGOLFF; JEFFERSON, 1974; SVENNEVIG, 2012a).

Os meios jurídico, médico e do jornalismo constituem exemplos característicos da fala institucional e revelam que a atividade desenvolvida pelos participantes de uma conversa altera a forma e as propriedades da organização de uma sequência de interação, assim como a formalidade de aspectos interacionais seus. No Quadro 2 estão delimitados os principais aspectos das reuniões formais.

Comparada à fala informal (ou cotidiana), a institucional tem um conjunto de estratégias interacionais reduzido e alta especialização (HERITAGE, 2004). Elas se diferenciam tanto no nível de organização da interação como no tipo de sistema de tomada de turno, quanto na linguagem, através do vocabulário utilizado.

\section{Quadro 1 - Caracterização dos empreendimentos investigados}

\begin{tabular}{|c|c|c|c|c|c|c|c|}
\hline & Cliente & $\begin{array}{c}\text { Contrato } \\
\text { iniciado em/ } \\
\text { Previsão de } \\
\text { entrega }\end{array}$ & $\begin{array}{c}\text { Tipologia e } \\
\text { características }\end{array}$ & $\begin{array}{l}\text { Data da } \\
\text { reunião de } \\
\text { partida }\end{array}$ & $\begin{array}{l}\text { Participantes da } \\
\text { reunião de partida de } \\
\text { instalações }\end{array}$ & $\begin{array}{l}\text { Situação do contrato } \\
\text { em agosto de } 2014\end{array}$ & Peculiaridades \\
\hline 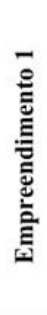 & $\begin{array}{l}\text { Cooperativa } \\
\text { habitacional }\end{array}$ & $\begin{array}{l}\text { Outubro de } \\
2012 / \text { sem } \\
\text { previsão }\end{array}$ & 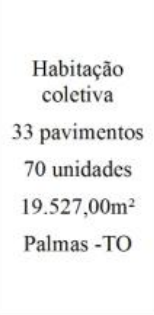 & $17 / 10 / 2013$ & $\begin{array}{c}\text { Diretor } \\
\text { Coordenador } \\
\text { Arquiteto responsável } \\
\text { Engenheiro-eletricista } \\
\text { Engenheiro de } \\
\text { instalações } \\
\text { hidrossanitárias } \\
\text { Cliente (representante) } \\
\text { Pesquisador }\end{array}$ & $\begin{array}{c}\text { Modificações } \\
\text { solicitadas para a } \\
\text { aprovação } \\
\text { comprometeram os } \\
\text { projetos arquitetônico e } \\
\text { estrutural iniciais. Um } \\
\text { novo pré-projeto } \\
\text { arquitetônico está em } \\
\text { elaboração e uma nova } \\
\text { reunião de partida será } \\
\text { necessária. }\end{array}$ & $\begin{array}{l}\text { Primeiro contrato do cliente com } \\
\text { o escritório } \\
\text { O representante do cliente nas } \\
\text { reuniões de coordenação é um } \\
\text { dos diretores da cooperativa que } \\
\text { é engenheiro civil. }\end{array}$ \\
\hline 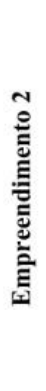 & $\begin{array}{l}\text { Incorporadora } \\
\text { e construtora }\end{array}$ & $\begin{array}{c}\text { Julho de } \\
2011 / \\
\text { setembro de } \\
2014\end{array}$ & 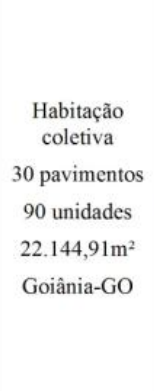 & $07 / 03 / 2014$ & $\begin{array}{c}\text { Diretor } \\
\text { Coordenador } \\
\text { Arquiteto responsável } \\
\text { Dois representantes do } \\
\text { escritório de projetos } \\
\text { complementares } \\
\text { Cliente (representante) } \\
\text { Pesquisador }\end{array}$ & $\begin{array}{l}\text { Foram superadas as } \\
\text { dificuldades relativas à } \\
\text { admissão de um novo } \\
\text { arquiteto responsável e } \\
\text { de um coordenador de } \\
\text { projetos no Escritório, } \\
\text { assim como as } \\
\text { demandas de ajustes } \\
\text { exigidos pelo trabalho } \\
\text { com a compatibilização } \\
\text { dos modelos. }\end{array}$ & $\begin{array}{l}\text { Contrato suspendido em } 2011 \\
\text { por dificuldades financeiras do } \\
\text { cliente e retomado em } 2012 \text {. } \\
\text { Quarto contrato do cliente com o } \\
\text { escritório. } \\
\text { O cliente contratou serviço de } \\
\text { gerenciamento virtual de } \\
\text { arquivos de projeto. } \\
\text { Primeiro projeto do cliente com } \\
\text { todos os projetos modelados. } \\
\text { Primeira experiência do } \\
\text { Escritório de compatibilizar } \\
\text { projetos em 3D. }\end{array}$ \\
\hline
\end{tabular}




\section{Quadro 2 - Aspectos e características das reuniões formais}

\begin{tabular}{|c|c|}
\hline Aspectos & Características \\
\hline \multirow{2}{*}{ Interacional } & $\begin{array}{r}\text { Duração, pauta (organização em tópicos), local de ocorrência e participantes } \\
\text { planejados com antecedência. }\end{array}$ \\
\cline { 2 - 3 } & $\begin{array}{r}\text { Sistema de tomada de turnos típico: alocação de turno mediada pelo condutor da } \\
\text { reunião (chair), também denominada pré-alocação de turno }\end{array}$ \\
\hline \multirow{2}{*}{ Institucional } & Participantes desempenham papéis (identidades) institucionais \\
\cline { 2 - 3 } & Possui um objetivo para os problemas institucionais tratados \\
\hline Físico & $\begin{array}{r}\text { Sala de reunião, mesa e cadeiras, disposição de participantes, recursos de } \\
\text { apresentação (projetores e documentos) e produtos (atas) }\end{array}$ \\
\hline
\end{tabular}

São três as características básicas da fala institucional:

(a) a reunião de identidades institucionais (participantes) com um objetivo específico;

(b) a existência de restrições que definem o que é possível de ser tratado no contexto em questão para que não haja fugas temáticas; e

(c) a orientação da interação por estruturas, estratégias e procedimentos particularizados, como se pode verificar nas entrevistas de programas de TV nas quais há regras para a fala de cada um dos participantes.

Ao entrevistador cabe perguntar, e ao entrevistado apenas responder, e não replicar (HERITAGE, 2004).

As identidades institucionais dos participantes, isto é, a atribuição de cada envolvido, também influenciam a interação e afetam a seleção de estruturas da fala e estratégias para se expressarem, o interesse em contribuir com o tema em pauta e a própria argumentação (DJORDJILOVIC, 2012). O condutor da reunião, por exemplo, não é apenas um organizador dos direitos da fala; a ele é atribuída uma autoridade para facilitar as ações, orientar a tomada de decisões, controlar as digressões e manter a progressão dos tópicos da pauta (EMMITT, 2010).

Entre os componentes da fala institucional as formulações (formulations) são as estratégias de maior interesse para o contexto do comprometimento porque são elaboradas com o intuito de se conquistar apoio e são dirigidas para um objetivo, sendo pouco frequentes na fala informal (BARNES, 2007). As formulações são exemplos de um recurso linguístico do qual os condutores das reuniões e gestores podem fazer uso de forma a orientarem as ações dos participantes para o estabelecimento de compromissos efetivos (CLIFTON, 2006).

As formulações servem também para recuperar discussões que perderam seu foco temático, para verificar e demonstrar entendimento compartilhado, para conduzir uma tomada de decisões, para expressar comentários e para elaborar finalizações. O excerto 1, cuja transcrição está apresentada na Figura 6, foi extraído dos dados da pesquisa e é um exemplo de formulação no qual se pode verificar:

(a) o uso do “então” como anunciador característico da formulação, que faz a ligação com os tópicos anteriores que lhe servem de referência; e

(b) a orientação de uma resposta concordante ou discordante dos interlocutores (BARNES, 2007).

\section{Procedimentos de análise das falas nas reuniões}

As ações desenvolvidas pelos participantes e a conduta deles na sequência de falas de cada reunião são descritas com base nos elementos da conversa estabelecidos pela AC, delineando o significado construído para cada interação, apesar de estarem inseridas num contexto com objetivos específicos: a reunião de coordenação.

As dimensões comportamentais propostas por Rousseau, Aubé e Savoie (2006) foram apontadas pelo exame dos sentidos resultantes das ações da fala e comparadas ao espectro de reações da Interaction Process Analysis (IPA), utilizada por Emmitt e Gorse (2007) para o estudo da interação em reuniões de projeto e gerenciamento da construção de empreendimentos no Reino Unido. A IPA relaciona, na escala progressiva apresentada na Figura 7, reações de caráter socioemocional positivo e negativo, intercaladas por outras de caráter funcional e neutro. 
Figura 6 - Exemplo de formulação

EXCERTO 1 - Empreendimento 2 [130-132]

1 DIR: [ então a gente ] teria que acrescentar mais uma etapa aqui=

2 PC2: =mais uma etapa [ ] uma etapa de estudo preliminar $(0.6)$ aí esse=

3 DIR: [umhum!]

Figura 7 - Escala de comportamentos da IPA

\begin{tabular}{|c|c|c|c|c|}
\hline \multicolumn{5}{|c|}{ Descrição das Categorias } \\
\hline 1 & \multicolumn{2}{|c|}{$\begin{array}{l}\text { DEMONSTRAR SOLIDARIEDADE - elevar a condição dos } \\
\text { outros agentes, dar ajuda, encorajar, reforçar (recompensar) } \\
\text { contribuições, cumprimentar de forma amigável, adotar gestos } \\
\text { sociais positivos. }\end{array}$} & $\mathrm{F}$ & \multirow{3}{*}{$\begin{array}{c}\text { Reações positivas. } \\
\text { Comportamentos usados } \\
\text { para encorajar } \\
\text { comprometimentos assim } \\
\text { como para construir e } \\
\text { fortalecer relacionamentos. }\end{array}$} \\
\hline 2 & \multicolumn{2}{|c|}{$\begin{array}{l}\text { DEMONSTRAR ALIVIO DE TENSÕES - risadas, } \\
\text { brincadeiras, satisfação, tentativa de reduzir tensões, expressar } \\
\text { entusiasmos, prazer e satisfação. }\end{array}$} & E & \\
\hline 3 & \multicolumn{2}{|c|}{$\begin{array}{l}\text { CONCORDÂNCIA - demonstrar aceitação passiva, identificar } \\
\text { a compreensão, cooperação, expressar interesse e } \\
\text { compreensão. }\end{array}$} & $\mathrm{D}$ & \\
\hline 4 & \multicolumn{2}{|c|}{$\begin{array}{l}\text { DAR SUGESTÕES - emitir sugestões firmes, indicar direção } \\
\text { ou resolução, dar autonomia aos outros, tentativa de controlar } \\
\text { direção ou decisões. }\end{array}$} & $\mathrm{C}$ & \multirow{3}{*}{$\begin{array}{l}\text { CAMPO FUNCIONAL: } \\
\text { NEUTRO } \\
\text { Informações e tentativa de } \\
\text { respostas. Atos usados para } \\
\text { desenvolver informações, } \\
\text { entendimento e controle. }\end{array}$} \\
\hline 5 & \multicolumn{2}{|c|}{$\begin{array}{l}\text { DAR OPINIÃO - oferecer opinião, avaliação, análise; } \\
\text { expressar um sentimento ou desejo; tentativa de analisar, } \\
\text { explorar, questionar; lançar ideias e justificativas. }\end{array}$} & B & \\
\hline 6 & \multicolumn{2}{|c|}{$\begin{array}{l}\text { DAR ORIENTAÇÃO - fundamentar ou prestar informação, } \\
\text { repetir, clarificar, confirmar; trazer informações relevantes } \\
\text { para a discussão, atos que contribuiam com o foco do grupo. }\end{array}$} & A & \\
\hline 7 & \multicolumn{2}{|c|}{$\begin{array}{l}\text { PEDIR ORIENTAÇÃO - pedir informação avançada, } \\
\text { repetição ou confirmação. Atos usados para pedir informação } \\
\text { relevante e para se compreender um assunto. }\end{array}$} & A & \multirow{3}{*}{$\begin{array}{l}\text { CAMPO FUNCIONAL: } \\
\text { NEUTRO } \\
\text { Questionamentos e pedidos. } \\
\text { Atos usados para } \\
\text { investigar, analisar e } \\
\text { explorar informações e } \\
\text { solicitações de direção. }\end{array}$} \\
\hline 8 & \multicolumn{2}{|c|}{$\begin{array}{l}\text { PEDIDO DE OPINIÃO - pedir opinião, avaliação e análise } \\
\text { alheia ou como o outro se sente. Atos usados para requisitar ou } \\
\text { explorar justificativas. }\end{array}$} & B & \\
\hline 9 & \multicolumn{2}{|c|}{$\begin{array}{l}\text { PEDIR SUGESTÕES - pedidos de sugestão, de direção e de } \\
\text { formas possiveis de ação. Solicitação de contribuições } \\
\text { decisivas, soluções e finalização de problemas. }\end{array}$} & $\mathrm{C}$ & \\
\hline 10 & \multicolumn{2}{|c|}{$\begin{array}{l}\text { DISCORDÂNCIAS - demonstrar rejeição passiva, } \\
\text { formalidade, resistir a ajuda, incapacidade de defender um } \\
\text { ponto de vista ou opinião, falha na proposição de visão } \\
\text { concorrente, rejeitar abordagem ou sugestão. }\end{array}$} & D & \multirow{3}{*}{$\begin{array}{c}\text { CAMPO } \\
\text { SOCIOEMOCIONAL } \\
\text { Reações negativas. } \\
\text { Comportamentos usados } \\
\text { para rejeitar informações } \\
\text { funcionais, questionar } \\
\text { comprometimentos e que } \\
\text { ameacem os } \\
\text { relacionamentos. }\end{array}$} \\
\hline 11 & \multicolumn{2}{|c|}{$\begin{array}{l}\text { DEMONSTRAR TENSÃO - evidenciar preocupação, } \\
\text { apreensão, insatisfação ou frustração. Interagentes tensos, no } \\
\text { limite. Atos que evidenciam sarcasmo ou condenação. }\end{array}$} & E & \\
\hline 12 & \multicolumn{2}{|c|}{$\begin{array}{l}\text { DEMONSTRAR ANTAGONISMO - atos usados para } \\
\text { denegrir atos alheios, para defender ou proteger-se, atacar } \\
\text { verbalmente ou dificultar ações alheias, expressões de } \\
\text { agressividade e raiva. }\end{array}$} & $F$ & \\
\hline A & Problemas de orientação & Problema & & \\
\hline $\begin{array}{l}\mathrm{B} \\
\mathrm{C}\end{array}$ & $\begin{array}{l}\text { Problemas de avaliação } \\
\text { Problemas de controle }\end{array}$ & $\begin{array}{l}\text { Problema d } \\
\text { Problemas }\end{array}$ & & $\begin{array}{l}\text { iamento de tensões } \\
\text { ração }\end{array}$ \\
\hline \multicolumn{2}{|c|}{$\begin{array}{l}\text { À medida que se progride de A para C muito } \\
\text { esforço é empreendido para o controle e a } \\
\text { finalização. }\end{array}$} & \multicolumn{3}{|c|}{$\begin{array}{l}\text { A intensidade emocional dos atos comunicativos } \\
\text { aumenta de D para E. }\end{array}$} \\
\hline
\end{tabular}


A comparação dos comportamentos apontados na análise das sequências de fala com a escala da IPA teve o objetivo específico de qualificar o caráter da conduta do participante, se favorável à interação, se neutro e funcional, ou se desfavorável à interação. Não se buscou identificar as observações a respeito dos comportamentos com as categorias estabelecidas pela IPA, que constitui um método que adota conceitos predefinidos a serem identificados e quantificados nas interações mediante a observação direta.

As considerações relacionadas à provável orientação das disposições individuais para o estabelecimento dos compromissos foram elaboradas associando-se as ações, os comportamentos e as habilidades comunicativas demonstradas pelos participantes da interação às definições (bases) do modelo de Meyer e Herscovitch (2001).

Apesar da observação e do registro integral das falas das RPI, foi transcrita apenas a parte das reuniões dedicada ao objetivo exclusivo de estabelecimento de compromissos de prazo entre os participantes. Mediante a análise completa das transcrições das RPI de E1 e E2 foram extraídas e detalhadas nove sequências de interação, denominadas trechos, seguindo os critérios apresentados no Quadro 3, dos quais apenas três são apresentados neste artigo.

\section{Análise e discussão de resultados}

\section{Coordenação de Projetos Complementares e as RPI}

Todas as atividades produtivas do escritório são contempladas pelo SGQ, que estabelece quatro registros relacionados à coordenação de projetos complementares: o manual de diretrizes do empreendimento, o CEP, o RDP e as atas das reuniões realizadas.

No escritório a contratação e a remuneração dos projetistas complementares são realizadas diretamente pelo cliente, cabendo ao escritório apenas orientar o trabalho deles. É de responsabilidade do representante do cliente 0 preenchimento do manual do empreendimento e o repasse das datas dos contratos firmados com os projetistas complementares para a elaboração do cronograma preliminar de atividades da coordenação.

Na Figura 8 apresenta-se o protocolo de desenvolvimento do projeto de arquitetura do escritório estudado. O projeto pré-executivo de arquitetura é a base sobre a qual os demais projetistas elaboram seus anteprojetos complementares (estruturas, sistemas prediais, entre outros), e o projeto executivo básico dá suporte para a produção dos projetos executivos das disciplinas complementares, e, por fim, ambos precisam estar compatibilizados com o projeto executivo final de arquitetura.

Quadro 3 - Critérios para seleção e análise dos trechos

\begin{tabular}{|l|}
\hline \multicolumn{1}{|c|}{ Aspectos determinantes na definição dos trechos detalhados } \\
\hline $\begin{array}{l}\text { a) Sequências de fala que evidenciam como são estabelecidos e ajustados os compromissos nas } \\
\text { equipes multidisciplinares de projeto de edificios. }\end{array}$ \\
\hline $\begin{array}{l}\text { b) Evidências de habilidades comunicativas e do uso de estratégias de interação para estimular o } \\
\text { envolvimento dos demais participantes ou para apontar contribuições aos assuntos em discussão. }\end{array}$ \\
\hline \multicolumn{1}{|c|}{ Aspestigados na análise dos trechos } \\
\hline estabelecimento do comprometimento?
\end{tabular}


Figura 8 - Protocolo de elaboração de projeto do escritório

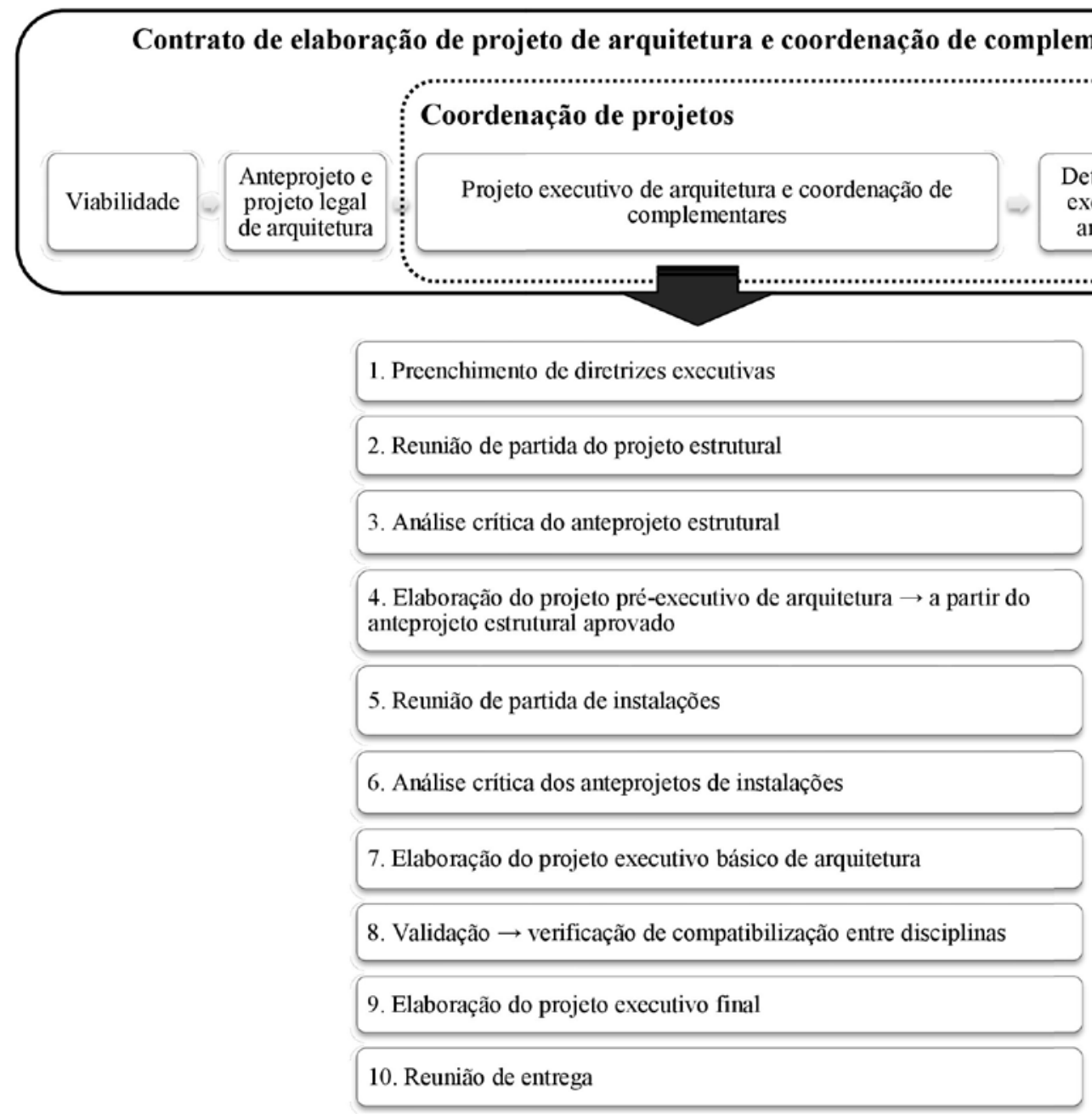

A partir do projeto pré-executivo de arquitetura compatibilizado com o anteprojeto estrutural a Coordenação de projetos realiza a RPI. Reúnem-se o diretor do escritório, o coordenador de projetos executivos e o arquiteto responsável pelo empreendimento, os responsáveis pelos projetos complementares de instalações contratados e os representantes do cliente para juntos estabelecerem:

(a) as diretrizes finais para a elaboração dos projetos executivos para o empreendimento, como a adoção de shafts, a localização de prumadas, equipamentos, entre outros; e

(b) o cronograma para a elaboração e entrega de projetos considerando as etapas do projeto executivo.

Esses dois temas constituem, nesta ordem, a pauta tratada na RPI, que tem duração de $2 \mathrm{~h}$ a $3 \mathrm{~h}$. O primeiro ponto envolve numerosos tópicos, e por isso a reunião é exaustiva. As reuniões que se seguem à RPI, como parte das atividades da coordenação de projetos, não necessariamente reúnem todos os projetistas das disciplinas complementares de instalações e são agendadas para o ajustamento de soluções técnicas específicas.

Dentro do protocolo de projetos do escritório, com o início do trabalho dos projetistas complementares, o gerenciamento dos compromissos e do projeto passa a ser monitorado pelo RDP. Esse documento e suas atualizações são remetidos para todos os participantes da equipe de projeto e permitem a verificação e o acompanhamento das datas-limite comprometidas para as entregas dos projetos e as alterações delas, caso aconteçam.

\section{Análise das RPI dos empreendimentos 1 e 2}

\section{Análise das interações e da organização do trabalho do escritório}

Os trechos apresentados a seguir são acompanhados de parte da análise realizada na pesquisa a fim de exemplificar a aplicação da técnica e destacar 
particularidades do estudo, já que em função de a interpretação das ações da conversa ser realizada ao longo da sequência de interação transcrita não há espaço suficiente neste artigo para a inserção completa da análise dos trechos. Assim, são expostos aqui a síntese e os resultados das análises realizadas.

Apesar de as falas nas reuniões não caracterizarem uma tipologia de conversa institucional específica, como a do meio jurídico, os recursos linguísticos mais utilizados para o estabelecimento do comprometimento puderam ser identificados. Nas duas reuniões estudadas o comprometimento foi estabelecido através de:

(a) perguntas;

(b) pedidos de comprometimento; $\mathrm{e}$

(c) formulações.

Na Figura 9 é apresentado o trecho 1. Na linha 3 o coordenador de projetos (COO) elabora um pedido de comprometimento com um prazo previamente estabelecido para a elaboração dos anteprojetos complementares. Na linha 8 o projetista de instalações hidrossanitárias (HID) toma o turno da fala e solicita um esclarecimento para que tenha condições de aceitar o pedido ou não.

Instigado na linha 4 pelo COO, o representante do cliente (CLI), na linha 12, provoca propondo um prazo impraticável para a elaboração do anteprojeto, o que gera risos nos participantes. Essa ação dentro do contexto da interação corresponde a uma estratégia de gerenciamento de tensão do grupo.

Nas linhas 17 e 24 os projetistas complementares de instalações elétricas (ELE) e HID fazem questionamentos com o intuito de avaliar o pedido feito pelo COO. CLI, na linha 30, entendendo que os esclarecimentos foram prestados, reelabora o pedido inicial feito por COO pela busca do comprometimento definitivo daqueles profissionais através de uma pergunta.

À pergunta de CLI apenas HID responde em forma de novo questionamento (linha 32), o que demonstra que há restrições para se estabelecer esse compromisso da forma expedita, seja por impossibilidade ou por ainda falta de informações. Atendido em seu questionamento, HID elabora, na linha 35, uma justificativa para sua dificuldade de comprometimento, enquanto ELE não emite qualquer opinião.

Considerando a resposta de HID (linha 35) e a falta de manifestação de ELE como demonstrações favoráveis ao pedido de comprometimento apresentado, CLI elabora uma formulação de síntese (linha 37) e considera os compromissos como aceitos pelos projetistas. Confirmação se efetua, pois nenhum dos projetistas contesta a formulação de CLI. A AC demonstra que formulações não contestadas são consideradas como aceitas, uma vez que o mecanismo da formulação é exigir do interlocutor um posicionamento diante do assunto (BARNES, 2007).

O trecho se encerra sem uma confirmação explícita do comprometimento de HID, sem uma promessa, enquanto ELE, que emitiu uma concordância (linha 25) que ficou sobreposta a outra fala, não a ratificou após a linha 37. O procedimento de HID e ELE, ao não externarem uma firme postura contrária à proposta de prazo realizada, exemplifica a forma discreta e ineficaz com que os comprometimentos são assumidos, a influência dos aspectos interacionais e as diferenças de habilidades comunicativas entre os participantes.

Na Figura 10 é apresentado outro trecho da RPI de E1 dedicado aos prazos para a elaboração dos projetos executivos. Essa sequência é iniciada com a proposição de um comprometimento a partir de uma pergunta feita pelo DIR (linha 1). Aqui não há um pedido de comprometimento em relação a um prazo estabelecido; é feita uma pergunta cuja resposta trará incorporada a confirmação do compromisso.

Novamente, diante da falta de um posicionamento firme e expresso de ELE e HID, CLI procura ordenar o comprometimento por meio de perguntas dirigidas ao DIR e ao COO (linhas 30 e 35). Diante da resposta emitida pelo COO, que é contestada pelo arquiteto responsável pelo desenvolvimento do projeto (ARQ) (linha 38), CLI elabora uma formulação de síntese para efetivar o comprometimento (linha 39), que é positivada pelo COO na linha seguinte. Novamente se percebe a postura proativa do CLI orientando a interação para a obtenção do comprometimento.

O uso desses três recursos para a elaboração dos compromissos relaciona-se às habilidades comunicativas dos participantes e ao repertório de estratégias interacionais que dominam. Como se constata nas análises dos trechos 1 e 2 e foi verificado no estudo da RPI do E2, os representantes dos clientes foram os agentes que demonstraram maior diversidade de estratégias interacionais, com expressividade superior à do condutor das reuniões, de quem se esperava o uso de variados recursos linguísticos para se alcançarem os objetivos da reunião e o comprometimento efetivo. 
Figura 9 - Trecho 1

TRECHO 1 - Empreendimento 1 [1-37] (início com 1 h35m52s de reunião)

DIR e o prazo agora (né)?

COO é::: eu anotei aqui:::: pra gente discutir::::

$>$ eu coloquei pra esta parte aqui de anteprojeto aqui de vocês $<$ quinze dias

o quê que você acha, CLI, também.

>quinze dias úteis, [ tá?< Não] é dias corridos não.

DIR [ ( ) ]

COO então são [ três semanas ]

HID [só do tipo ou: ] ou:::

$(0.9)$

DIR [ ${ }^{\circ}$ (não, tudo? $\left.)^{\circ}\right]$

$\operatorname{COO}\left[{ }^{\circ}\right.$ (tudo) $\left.{ }^{\circ}\right]=$

CLI =pode vê com eles? que as vezes vocês vão fazer em menos né? $(0.8)$

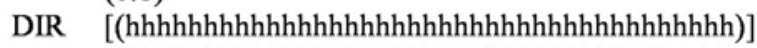

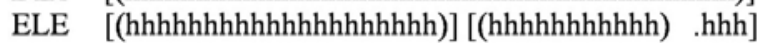

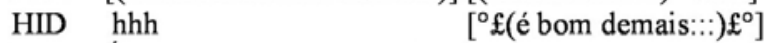

ELE É só lançar os pontos, né?=

DIR =é? e assim:: a gente tá contando a partir do momento que vocês receberem::: [o material da gente]. é?

COO $\left.\quad\left[{ }^{\circ} \text { (os:: arquivos }\right)^{\circ}\right]$

$(1.4)$

ELE tá?

COO quinze dias uteis. $=$

HID = mas [é bem::] básico mesmo né?

ELE [tá bom.]

COO é:: [é só o lança]mento (.) plantas sem detalhes nen[hum. ]

HID [bem:: básico.] [só pra]

ver as interferências depois o resto vem no::: [ ao final ] né?

CLI é quinze dias vamos falar oh?(.) é quinze dias ou: menos

quê que vocês [acham, que eu-]

HID [ quinze dias- ] quinze dias u:::teis né?

DIR u::teis três semanas=

COO =três semanas $=$

HID =menos que isso não dá não (0.4) tem cobertura:: (1.0) área comum::: (0.7) demorado.

CLI tá okay então >tá seguindo aí?< 
Figura 10 - Trecho 2

TRECHO 2 - Empreendimento 1 [48-89] (início com $1 \mathrm{~h} 37 \mathrm{m08s}$ de reunião)

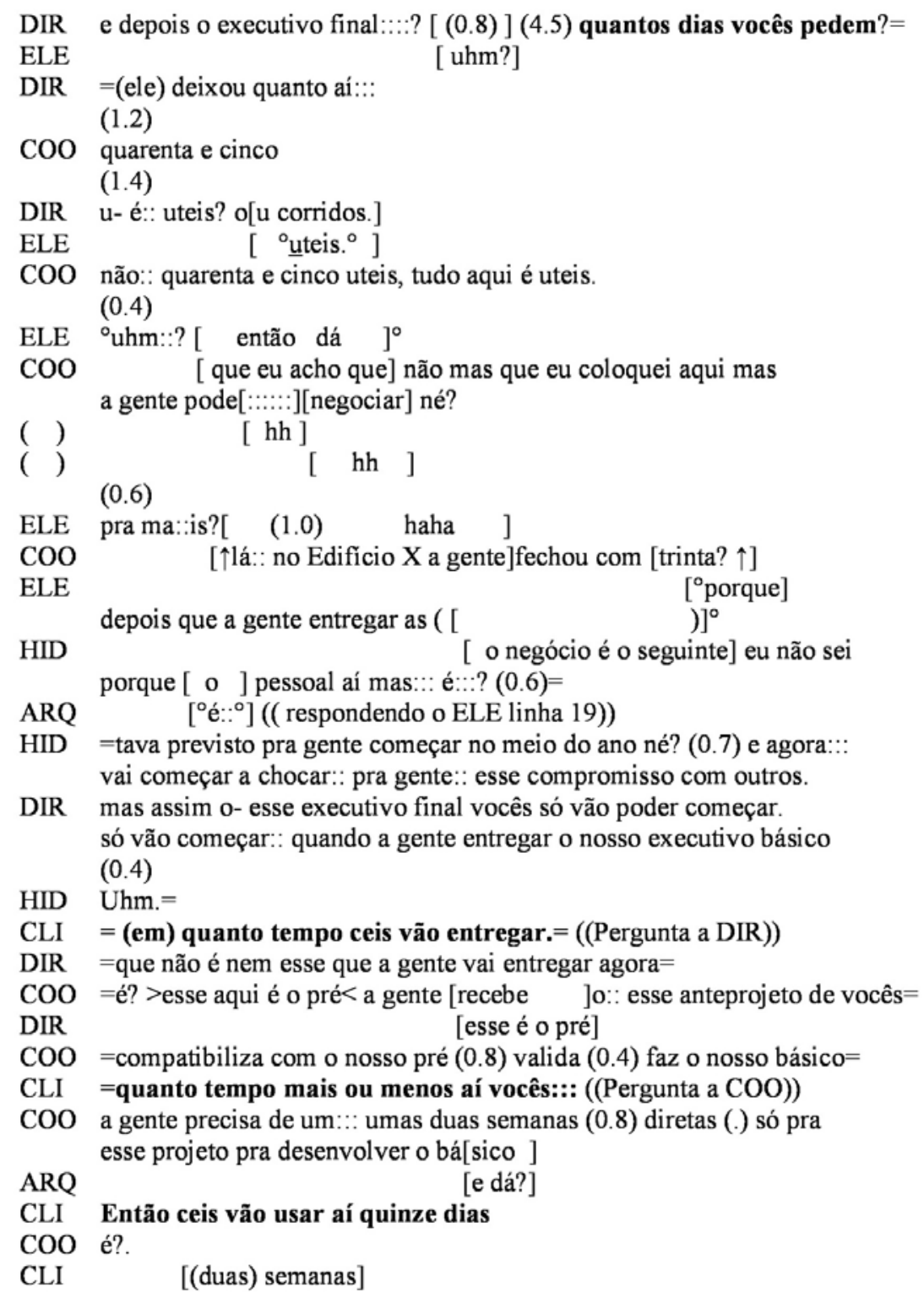

O destaque observado quanto aos representantes dos clientes alinha-se ao que apontaram Emmitt e Gorse (2007) no estudo de reuniões da construção civil inglesa. Estes agentes fizeram uso de brincadeiras durante a fala para aliviar tensões surgidas no grupo e demonstraram empatia e solidariedade para conseguir o comprometimento estimulando a tomada de decisão de outros agentes.

Outros participantes, contudo, estavam em condição inversa, como os projetistas de instalações elétricas e hidrossanitárias do E1, que demonstraram restritas habilidades comunicativas com o desenvolvimento de seus turnos de forma fracionada, propondo comprometimentos sem efetividade, exigindo ações de confirmação por parte dos interlocutores, o que pode se verificar em parte nas análises dos trechos 1 e 2.

A análise das transcrições das duas RPI permitiu perceber que o diretor do escritório, como condutor das duas reuniões estudadas, ainda que demonstrando possuir habilidades de comunicação e utilizando estratégias de interação variadas nas reuniões, não atuou como facilitador da conversa.

O condutor não facilitou a participação dos agentes com menores habilidades de comunicação orientando suas interações; não oportunizou de 
forma regular aos participantes a elaboração de pedidos de esclarecimento antes de formulações que objetivavam encerrar a discussão de um tema e não marcou os comprometimentos estabelecidos com formulações de síntese, de modo que, ao resumir a argumentação, os demais declarassem seu posicionamento favorável ou contrário à decisão proposta. Pode-se apontar que a condução da reunião foi realizada, mas não a liderança do grupo, como esclarecem Bambacas e Patrickson (2008) e Zeffane et al. (2011).

O trecho 8, na Figura 11, revela ações e condutas dos participantes alinhadas com a dimensão de comportamentos funcionais de colaboração delineada por Rousseau, Aubé e Savoie (2006). Na linha 1 o representante do cliente (CLI1) expõe que o pedido que lhe é feito imporá dificuldades, circunstância com a qual o projetista complementar (PC2) demonstra-se solidário (na linha 4), respondendo antes mesmo de aquele concluir seu turno, o que caracteriza a estrutura da fala denominada affiliative action. Em função disso, na linha 6, PC2 espontaneamente oferece ajuda a CLI1 e novamente, na linha 20 , reforça sua disposição em ajudar com uma formulação que encerra o assunto.

Para o contexto de E2, solidariedade e disposição são estratégicas para que PC2 demonstre para CLI1 que os serviços que lhe são oferecidos (de elaboração dos projetos de instalações a partir de modelagem) são importantes e devem ser adequadamente subsidiados para que proporcionem vantagens reais. Assim, PC2 procura conquistar a confiança de CLI1 e valorizar o trabalho que executa.
Nas RPI dos dois empreendimentos a estrutura da conversa assemelhou-se à da fala informal apesar do caráter funcional da interação, percebido e assumido por todos. Confirma essa observação o fato de a condução das reuniões não ter sido rigorosa nem caracteristicamente formal, sem quaisquer sanções às falas dos demais participantes por parte do condutor, nem às fugas temáticas ou falas longas, tanto quanto a predominância da autosseleção como sistema de tomada de turnos em vez da típica pré-alocação de turnos, como acontece em reuniões em que há um condutor. Destaca-se ainda que em nenhuma das reuniões ocorreram falas caracterizáveis como turnos específicos, à semelhança de um discurso, e nem foi seguida uma progressão temática rígida.

A pouca formalidade da reunião também pareceu interferir na efetividade do encontro, pois se verificou que, após o encerramento formal das reuniões, novos pedidos de informações foram feitos entre os participantes sem quaisquer registros nos documentos da reunião, o que pode indicar também que alguns tópicos abordados durante a reunião não foram exauridos.

As convocações também contribuem para a relativa informalidade das RPI porque foram realizadas via e-mail ou telefone e continham apenas a data, o local e o horário de início. Não foi informada a pauta, e nenhum documento discutido durante a reunião foi enviado ao grupo para apreciação prévia ou como subsídio para posicionamento individual. O próprio posicionamento dos participantes na mesa, que não teve a mesma orientação nas duas reuniões, ordenando-se de maneira aleatória, revela a pouca formalidade da organização estabelecida para o encontro.

\section{Figura 11 - Trecho 8}

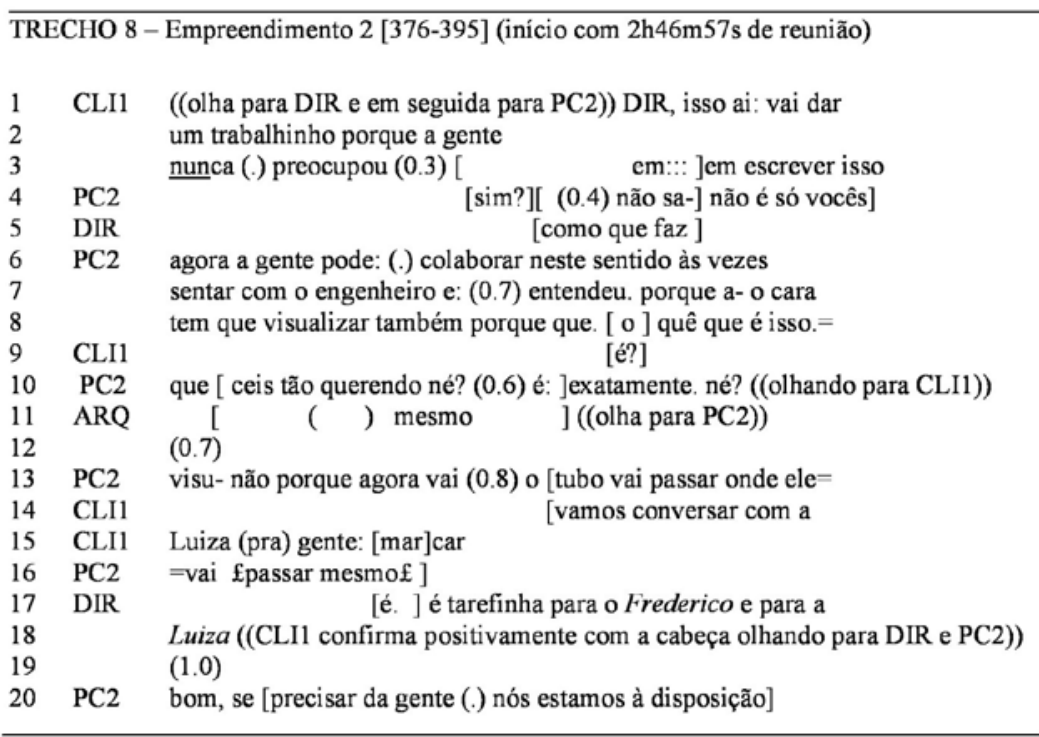


O tipo de desenvolvimento de projeto que marcou cada empreendimento também influenciou os resultados das reuniões. A RPI do E1 foi mais produtiva e ordenada que a reunião do E2 porque os agentes do E1 já estavam habituados com a produção tradicional de projeto, com a compatibilização sendo feita com a sobreposição de desenhos, enquanto no E2 o projeto passaria a ser compatibilizado a partir de modelos virtuais, e a RPI aconteceu sem que um encontro anterior tivesse ocorrido para que esclarecimentos sobre a nova prática fossem prestados e discutidos.

Por essa razão, a RPI do E2 acabou sendo dedicada ao nivelamento de conceitos e ao estabelecimento de novos marcos e fases, sem os quais a discussão de etapas e prazos não teria proveito, uma vez que o representante do cliente e o escritório de arquitetura ainda não haviam participado de projetos com essa particularidade. A reunião do E2 foi finalizada sem a revisão do cronograma preliminar, que é objeto da pauta da RPI, o que só foi realizado posteriormente via e-mail.

Quanto à contribuição dos registros documentais para a efetividade do comprometimento, foi constatado que nem todas as decisões tomadas pelo grupo através da fala foram registradas nos documentos e que nem tudo o que se discutiu foi satisfatoriamente resolvido. No E1, por exemplo, o cronograma preliminar não foi alterado após a reunião apesar de ter sido discutida a inviabilidade de prazo apresentado para a entrega dos projetos de instalações hidrossanitárias. Essa situação demonstrou que os documentos relacionados à RPI pouco contribuem para o estabelecimento do comprometimento eficaz, ainda que estruturados pelo SGQ.

Os procedimentos e protocolos previstos no SGQ não facilitaram a ação colaborada dos membros do grupo para a obtenção dos objetivos do encontro com efetividade, sendo parte das atividades que poderiam ser realizadas de forma coletiva de atribuição do diretor do escritório e do coordenador de projetos. O planejamento da forma de trabalho e a avaliação dos objetivos da coordenação para o projeto, se realizados coletivamente, facultariam ações na interação alinhadas com as dimensões de preparação da condução do trabalho e de comportamentos de ajuste da equipe do modelo de Rousseau, Aubé e Savoie (2006).

\section{Sentido construído pela interação e a prática da coordenação de projetos}

Nas RPI estudadas um sentido resultante das ações da sequência da interação que merece destaque é a atuação dos representantes dos clientes contrária aos objetivos da coordenação de projetos. Nos dois empreendimentos analisados, os representantes dos clientes agiram de forma a comprometer a entrega do conjunto completo e compatibilizado de projetos à obra de modo a sustentar as vantagens do processo de coordenação ao destacarem a urgência para o início das obras e o interesse em apressar os projetos, fosse flexibilizando os conteúdos das entregas, como no E1, fosse determinando um prazo de entrega muito curto, como no E2. Com esse procedimento os representantes dos clientes inviabilizam o serviço para o qual estavam pagando o escritório para realizar.

\section{Síntese e proposições}

A análise das interações destaca a influência dos aspectos da conversa sobre os registros e procedimentos do processo de projeto do escritório no estabelecimento dos compromissos. O contexto analisado não facilitou a efetiva colaboração entre os agentes em função da organização da prática de trabalho, nem estratégias interacionais específicas como as formulações de síntese foram adotadas sistematicamente como ferramentas a favor do comprometimento.

O caráter objetivo e funcional das interações investigadas caracterizam um contexto em que as oportunidades de ouvir o outro são escassas, como descrito por Emmitt e Gorse (2007). A prática da coordenação de projetos complementares no escritório não estabelece tempo ou circunstâncias reservadas para a troca de experiências e para a assistência mútua, nem está estruturada para uma participação maior dos agentes envolvidos.

A pouca formalidade da estrutura e da condução das reuniões refletiu-se na efetividade do comprometimento. A falta de maior rigor no controle da sucessão dos tópicos oportunizou a ocorrência de fugas temáticas, que não foram cerceadas pelo condutor da reunião, comprometendo propostas de formulações e cenários orientados para a tomada de decisões, como relatado por Svennevig (2012b). As convocações, por sua vez, não foram acompanhadas por documentos de apoio aos participantes.

A partir desta análise, destacaram-se duas vertentes de ação para o aprimoramento do comprometimento no processo de gestão de projetos estudado: uma relacionada a aspectos comunicativos e da interação, e outra que diz respeito a aspectos formais e materiais da prática da coordenação de projetos. Para cada vertente foram definidas medidas práticas, relacionadas no Quadro 4. 


\section{Quadro 4 - Medidas práticas a favor do comprometimento}

\begin{tabular}{|c|c|}
\hline Aspectos Comunicativos e da Interação & Aspectos formais e materiais da prática \\
\hline $\begin{array}{l}\text { É desejável um tempo programado nos encontros } \\
\text { da coordenação de projeto para troca de } \\
\text { experiências e compartilhamento valores, } \\
\text { facultando a colaboração. }\end{array}$ & $\begin{array}{l}\text { As convocações para as reuniões devem ser } \\
\text { formais, completas e acompanhadas de material de } \\
\text { subsidio para que os participantes prepararem-se } \\
\text { para a negociação. }\end{array}$ \\
\hline \multirow{2}{*}{$\begin{array}{l}\text { Os condutores das reuniões devem ter suas } \\
\text { habilidades comunicativas desenvolvidas e domínio } \\
\text { de amplo repertório interacional para serem } \\
\text { efetivos facilitadores da tomada de decisão e } \\
\text { agentes da integração, fortalecendo as relações } \\
\text { interpessoais e suplantando as deficiências dos } \\
\text { demais participantes em favor dos resultados do } \\
\text { projeto. }\end{array}$} & $\begin{array}{l}\text { A condução das reuniões deve ser formal e rigorosa, } \\
\text { com sanções aos participantes, quando oportunas, } \\
\text { para minimizar fugas temáticas, reparos sucessivos, } \\
\text { oportunizar maior participação e melhor } \\
\text { aproveitamento do tempo do encontro sem } \\
\text { estendê-lo, esgotar os participantes ou prejudicar os } \\
\text { resultados. }\end{array}$ \\
\hline & $\begin{array}{l}\text { Elaborar formas de registro de informações para as } \\
\text { reuniões adequadas às circunstâncias pelas quais a } \\
\text { informação é gerada e em função de como será } \\
\text { utilizada. }\end{array}$ \\
\hline $\begin{array}{l}\text { Formulações de confirmação ou sintese devem ser } \\
\text { ferramentas de uso sistemático, sobretudo, dos } \\
\text { condutores das reuniões por serem construções } \\
\text { interacionais importantes para o comprometimento } \\
\text { eficaz. }\end{array}$ & $\begin{array}{l}\text { Devem ser desenvolvidos recursos de suporte ao } \\
\text { comprometimento para apoio a tomada de decisão, } \\
\text { com forte apelo visual e facilmente editáveis, para } \\
\text { uso em tempo real nas reuniões. }\end{array}$ \\
\hline
\end{tabular}

As proposições estão estruturadas entendendo-se o gerenciamento do comprometimento como uma ferramenta de gestão, como apontaram Sull e Spinosa (2007), suportadas pelos aspectos estruturais e comunicativos da interação, destacados por Bambacas e Patrickson (2008) e Zeffane, Tipu e Ryan (2011). Incorporadas à prática de trabalho já existente no escritório, essas medidas particularizam o gerenciamento do compromisso, como proposto pela abordagem Lean Design Management (EL REIFI; EMMITT, 2011; EMMITT; PASQUIRE; MERTIA, 2011), ampliam o escopo de ferramentas de gestão do escritório com estratégias relacionadas a aspectos de comunicação e de relacionamento pessoal (CRAWFORD; POLLACK, 2004; SILVA et al., 2016) e escapam à conformação de sistemas de gestão informatizados para os quais o protocolo de trabalho do escritório precisaria ser adaptado, como alertam Ericksson e Lind (2005).

\section{Conclusões}

Este estudo proporcionou a compreensão dos aspectos do comprometimento relacionados à interação e à contribuição deles para a efetividade dos compromissos. A investigação da ação promovida pela fala no contexto de trabalho estudado, subsidiada pelas considerações advindas da literatura, permitiu a definição de medidas práticas voltadas para o refinamento da gestão da coordenação de projeto do estudo de caso em apoio às ferramentas já adotadas pelo escritório.
A interação, como instrumento de comprometimento que precede os registros documentais, relativiza a contribuição de protocolos e de ferramentas de controle adotadas para o processo, assim como a confiabilidade das informações documentadas quando não são desenvolvidas para o próprio processo.

O uso da AC resultou em três contribuições relevantes:

(a) de que o comprometimento é também estabelecido por outras ações do processo interativo a partir das estruturas da fala, que não somente através de pedidos e promessas, como definido pelo ciclo de comprometimento;

(b) a compreensão da prática da coordenação de projetos a partir do sentido construído pelo entendimento e pelas ações dos envolvidos; e

(c) a influência das habilidades comunicativas para a efetividade do comprometimento, cuja importância tem sido apontada pela literatura relativa à liderança, que não são destacadas pelo ciclo de comprometimento.

A análise da conversa tornou visível que diferentes agentes do processo fazem uso de distintas estratégias de comunicação para estruturarem o contexto e o conteúdo da conversa, conduzindo o curso das ações resultantes para os interesses que considerem determinantes.

Destaca-se como contribuição desta pesquisa a investigação dos aspectos da interação direta no âmbito da equipe de projeto de edifícios, somando- 
a à abordagem dos trabalhos nacionais correlatos dedicados à produção no canteiro de obra.

O avanço obtido nesta pesquisa foi o aprofundamento na estrutura da linguagem e da comunicação, o que permitiu examinar o elemento central da conversa voltada para a produção que é o compromisso. Investigou-se não só a caracterização do compromisso na fala a partir da análise da conversa, mas também seus aspectos antecedentes sediados no íntimo dos agentes envolvidos, suportados pelos modelos provenientes da literatura específica

O estudo de interações na construção civil que envolvam outros agentes como operários e fornecedores, a partir da AC, pode contribuir para o aprofundamento do conhecimento sobre o comprometimento desenvolvido nesta pesquisa no âmbito da engenharia civil. Pesquisas que façam uso de amostragens maiores facultarão a identificação de eventuais estratégias de interação específicas do meio profissional da construção civil, como já constatadas nos campos jurídico e médico.

\section{Referências}

BAIDEN, B. K.; PRICE, A. D. F.; DAINTY, A. R. J. The Extent of Team Integration Within the Construction Projects. International Journal of Project Management, v. 26, p. 13-23, 2006.

BALLARD, H. G. The Last Planner System of Production Control. Birmingham, 2000. Tese (Doutorado em Engenharia Civil) - Escola de Engenharia Civil, Faculdade de Engenharia, Universidade de Birmingham, Birmingham, 2000.

BALLARD, H. G.; ZABELLE, T. Lean Design: process, tools and techniques. White Paper n. 10, Lean Construction Institute, 2000.

BAMBACAS, M.; PATRICKSON, M. Interpersonal Communication Skills That Enhance Organizational Commitment. Journal of

Communication Management, v. 12, n. 1, p. 5172, 2008.

BARNES, R. Formulations and the Facilitation of Common Agreement in Meeting talk. Text and Talk, v. 27, n. 3, p. 273-296, 2007.

BLOIS, M. D. et al. Clients and Participants of the Building Industry: structures and mechanisms of coordination and communication. Architectural Engineering and Design Management, v. 7, p. 322, 2011.

CLIFTON, J. A Conversation Analytical Approach to Business Communication: the case of leadership. Journal of Business Communication, v. 43, n. 3, p. 202-219, 2006.
COSTA, A. C. F. Diretrizes para o

Desenvolvimento da Comunicação no Gerenciamento de Projetos Enxutos da Construção: uma perspectiva da linguagem-ação. Florianópolis, 2007. Dissertação (Mestrado em Engenharia Civil) - Programa de Pós-Graduação em Engenharia Civil, Universidade Federal de Santa Catarina, Florianópolis, 2007.

CRAWFORD, L.; POLLACK, J. Hard and Soft Projects: a framework for analysis. International Journal of Project Management, v. 22, n. 8, p. 645-653, 2004.

DJORDJILOVIC, O. Displaying and Developing Team Identity in Workplace Meetings: a multimodal perspective. Discourse Studies, v. 14, n. 1, p. 111-127, 2012.

EL REIFI, M. H.; EMMITT, S. Lean Design Management: exploring perception and practice. In: ARCHITECTURAL MANAGEMENT IN THE DIGITAL ARENA, Viena, 2011. Proceedings... Eindhoven: University Press, 2011.

EMMITT, S. Managing Interdisciplinary Projects. New York: Spon, 2010.

EMMITT, S.; GORSE, C. A. Communication in Construction Teams. New York: Taylor \& Francis, 2007.

EMMITT, S.; PASQUIRE, C.; MERTIA, B. Addressing the Architect/Contractor Interface: a lean design management perspective. In: ARCHITECTURAL MANAGEMENT IN THE DIGITAL ARENA, Viena, 2011. Proceedings... Eindhoven: University Press, 2011.

ERICKSSON, O.; LIND, M. Problems With Communication Quality in Commitment Management. In: INTERNATIONAL WORKSHOP ON COMMUNICATION AND COORDINATION IN BUSINESS PROCESSES, Kiruna, 2005. Proceedings... Kiruna, 2005.

GAGO, P. C. Questões de Transcrição em Análise da Conversa. Veredas, Juiz de Fora, v. 6, n. 2, p. 89-113, 2002.

GHASSEMI, R.; BECERIK-GERBER, B. Transitioning to Integrated Project Delivery: potential barriers and lessons learned. Lean Construction Journal, Special Issue, p. 32-52, 2011.

GOLDKUHL, G. Conversational Analysis as a Theorical Foundation for Language Action Approaches: In: INTERNATIONAL WORKING CONFERENCE ON THE LAP ON COMMUNICATION MODELING, Tilburg, 2003. Proceedings... Tilburg, 2003. 
GOODWIN, C.; HERITAGE, J. Conversation Analysis. Annual Review of Anthropology, v. 19, p. 283-307, 1990.

GORSE, C. A.; EMMITT, S. Informal Interaction in Construction Progress Meeting. Construction Management and Economics, v. 27, n. 10, 2009.

HERITAGE, J. Conversation Analisys and Institutional talk. In: SANDERS, R.; FITCH, K. (Eds.). Handbook of language and social interaction. Mahwah NJ: Erlbaum, 2004.

LUCK, R. Does This Compromise Your Design? Interactionally producing a design concept in talk. CoDesign, v. 5, n. 1, p. 21-34, 2009.

MACOMBER, H.; HOWELL, G. A. Linguistic Action: contributing to the theory of lean construction. In: ANNUAL CONFERENCE OF THE INTERNATIONAL GROUP FOR LEAN CONSTRUCTION, 11., Virginia, 2003. Proceedings... Virginia, 2003.

MATTHEWS, B.; HEINEMANN, T. Analysing Conversation: studying design as social action. Design Studies, v. 33, p. 649-672, 2012.

MEYER, J. P.; HERSCOVICH, L. Commitment in Workplace: toward a general model. Human Resource Management Review, v. 11, p. 299326, 2001.

MITIDIERI, C. V.; MANSO, M. A. Gestão e Coordenação de Projetos em Empresas Construtoras e Incorporadas: da escolha do terreno à avaliação pós-ocupação. São Paulo: Pini, 2011.

OAK, A. "You Can Argue it Two Ways": the collaborative management of a design dilemma. Design Studies, v. 33, p. 630-648, 2012.

OAK, A. What Can Talk Tell us About Design? Analyzing conversation to understand practice. Design Studies, v. 32, p. 211-234, 2011.

OLIVEIRA, C. R. Comunicação e Gestão de Obras: a dinâmica textos/conversações baseado no estudo de dois empreendimentos habitacionais. Florianópolis, 2010. Tese (Doutorado em Engenharia Civil) -Programa de Pós-Graduação em Engenharia Civil, Universidade Federal de Santa Catarina, Florianópolis, 2010.

OTTER, A. D.; EMMITT, S. Design Team Communication and Design Task Complexity: the preference for dialogues. Architectural Engineering and Design Management, v. 4, p. 121-129, 2008.
ROUSSEAU, V.; AUBÉ, C.; SAVOIE, A. Teamwork Behavior: a review and an integration of frameworks. Small Group Research, v. 37, n. 5, p. 540-570, 2006.

SACKS, H.; SCHEGOLFF, E.; JEFFERSON, G. A Simplest Systematics for the Organization of Turn Taking for Conversation. Language, v. 50, n. 4, p. 696-735, 1974.

SCHEGLOFF, E. A. Harvey Sacks: lectures 19641965: an introduction/memoir. Human Studies, v. 12, p. 185-209, 1989.

SILVA, C. R.; ANDRADE, D. N.; OSTERMANN, A. C. Análise da Conversa: uma breve introdução. ReVEL, v. 7, n. 13, 2009.

SILVA, D. A. R. et al. Aspectos Comportamentais da Gestão de Projetos: uma análise bibliométrica (1988-2014). Gestão e Produção, jan. 2016.

SULL, D. N.; SPINOSA, C. Promise-Based Management: the essence of execution. Harvard Business Review, apr. 2007.

SVENNEVIG, J. Interaction in Workplace Meeting. Discourse Studies, v. 14, n. 1, p. 3-10, 2012a.

SVENNEVIG, J. The Agenda as Resource For Topic Introduction in Workplace Meetings.

Discourse Studies, v. 14, n. 1, p. 53-66, 2012b.

VIANA, D. D.; FORMOSO, C. T.; ISATTO, E. L. Modelling the Network of Commitments in the Last Planner System. In: ANNUAL CONFERENCE OF THE INTERNATIONAL GROUP FOR LEAN CONSTRUCTION, 19., Lima, 2011. Proceedings... Peru, 2011.

WEIGAND, H.; POLL, F. V. D.; MOOR, A. D. Coordination Through Communication. In: INTERNATIONAL CONFERENCE ON THE LANGUAGE-ACTION PERSPECTIVE ON COMMUNICATION MODELLING, 8., Tilburg, 2003. Proceeding... Tilburg, 2003.

ZEFFANE, R.; TIPU, S. A.; RYAN. J. C. Communication, Commitment and Trust: exploring the triad. International Journal of Business and Management, v. 6, n. 6, 2011.

ZERVAJ, V.; HARTMANN, T.; ACHAMMER, C. Managing the Process of Interdisciplinary Design: identifying, enforcing, and anticipating decision-making frames. Architectural Engineering and Design Management, v. 9, n. 2, p. 121-133, 2013. 


\section{Vinícius Carrião dos Santos}

Departamento de Áreas Acadêmicas III - Engenharia Civil | Instituto Federal de Educação, Ciência e Tecnologia de Goiás | Rua 75, 46, Câmpus Goiânia, Centro | Goiânia - GO - Brasil | CEP 74055-110 | Tel.: (62) 3227-2700 | E-mail: vinicius.arquiteto@ifg.edu.br

\section{Tatiana Gondim Amaral}

Escola de Engenharia Civil | Universidade Federal de Goiás | Praça Universitária, s/n, Setor Universitário | Goiânia - G0 - Brasil | CEP 74605-220 | Tel.: (62) 3209-6084 | E-mail: tatiana_amaral@hotmail.com

\section{J osé de Paula Barros Neto}

Departamento de Engenharia Estrutural e Construção Civil, Centro de Tecnologia | Universidade Federal do Ceará | Campus do Pici, s/n, Bloco 710, Pici | Fortaleza - CE - Brasil | CEP 60455-760 | Tel.: (85) 3366-9600 | E-mail: barrosneto@gercon.ufc.br

\section{Revista Ambiente Construído}

Associação Nacional de Tecnologia do Ambiente Construído

Av. Osvaldo Aranha, 99 - 3o andar, Centro

Porto Alegre - RS - Brasil

CEP $90035-190$

Telefone: +55 (51) 3308-4084

Fax: +55 (51) 3308-4054

www. seer. ufrgs. br/ ambienteconstruido

E-mail: ambienteconstruido@ufrgs.br 